\title{
Comparison of different doses of anti-human T-lymphocyte immunoglobulin for graft versus host disease prophylaxis in pediatric unrelated hematopoietic stem cell transplantation
}

\author{
Didem Atay ${ }^{1}$, Arzu Akçay ${ }^{2}$, Fatma Demir Yenigürbüz², Burcu Akıncı², Konul Bagirova², \\ Samira Hasanova ${ }^{2}$, and Gulyuz Ozturk ${ }^{2}$ \\ ${ }^{1}$ Acibadem University \\ ${ }^{2}$ Acibadem University, Pediatric Hematology/Oncology/BMT Unit Altunizade
}

October 26, 2020

\begin{abstract}
Background: Graft versus host disease is a major cause of morbidity and mortality after allogeneic HSCT from unrelated donors. ATLG is commonly used as prophylaxis for GVHD. The studies according to optimum dose of ATLG especially in pediatric patients are limited. Patients and Methods: Outcomes of 158 pediatric patients, who received ATLG as GVHD prophylaxis for matched unrelated donor HSCT at a dose of $10 \mathrm{mg} / \mathrm{kg}$ (group 1), $20 \mathrm{mg} / \mathrm{kg}$ (group 2) and $30 \mathrm{mg} / \mathrm{kg}$ (group 3) were analyzed retrospectively. The median duration of follow-up was 25.25 months (range, 1.1-79.5 months). Results: The incidences of acute and chronic GVHD were statistically not different between three groups ( $\mathrm{p}=0.55$ and $\mathrm{p}=0.45)$. But TRM at day 100 and OS at the end of follow-up was found significant inferior in patients received ATLG $10 \mathrm{mg} / \mathrm{kg}(\mathrm{p}=0.006, \mathrm{p}=0.004)$. Cox regression analysis showed that ATLG dose of $10 \mathrm{mg} / \mathrm{kg}$ (hazard ratio [HR] 0.500 [95\% CI 0.301-0.829]; $\mathrm{p}=0.007$ ), severe acute GVHD (HR 5.512 [2.027-14.993]; $\mathrm{p}=0.001$ ), and having viral infection (HR 2.510 [1.034-6.089]; $\mathrm{p}=0.042$ ) were significant prognostic factors for inferior OS. Conclusion: Although ATLG dose of $10 \mathrm{mg} / \mathrm{kg}$ is effective in pediatric patients on acute and chronic GVHD prevention and safe from the point of infection; TRM and OS were superior in ATLG doses [?]20 mg/kg with no difference between $20 \mathrm{mg} / \mathrm{kg}$ and $30 \mathrm{mg} / \mathrm{kg}$. So, it could be better to choose ATLG dose of $20 \mathrm{mg} / \mathrm{kg}$ in conditioning regimen for MUD HSCT in pediatric patients, but these observations should be supported with other multicenter prospective studies including larger patient population.
\end{abstract}

Comparison of different doses of anti-human T-lymphocyte immunoglobulin for graft versus host disease prophylaxis in pediatric unrelated hematopoietic stem cell transplantation

Didem Atay, $\mathrm{MD}^{1}$, Arzu Akcay, MD¹, Fatma Demir Yenigürbüz, $\mathrm{MD}^{1}$, Burcu Akinci, $\mathrm{MD}^{1}$, Konul Bagirova, $\mathrm{MD}^{1}$, Samira Hasanova, $\mathrm{MD}^{1}$, Gulyuz Ozturk, $\mathrm{MD}^{1^{*}}$

${ }^{1}$ Department of Pediatric Hematology/Oncology \& Bone Marrow Transplantation Unit, Acıbadem University, School of Medicine, Altunizade Hospital

* Correspondence to: Gulyuz Ozturk

Adress: Erenköy mah, Azim sok, Murat apt. No:4 D:4, Kadıköy, İstanbul, Turkey

E-mail: gulyuzo@gmail.com

Abstract word number: 253

Main text word number: 3048

Number of tables: 4 
Number of figures: 1

Running title: ATLG in pediatric MUD HSCT

Keywords: ATLG, OS, pediatric MUD HSCT

Abbreviations:

\begin{tabular}{ll}
\hline GVHD & Graft versus host disease \\
\hline HSCT & hematopoietic stem cell transplantation \\
ATG & Antithymocytes globulin \\
ATLG & Anti-human T-lymphocyte immunoglobulin \\
MUD & matched unrelated donor \\
TRM & transplant related mortality \\
OS & overall survival \\
RFS & Relapse free survival \\
HLA & human leukocyte antigen \\
CSA & cyclosporine \\
MTX & methotrexate \\
MMF & Mycophenolate mofetil \\
CMV & Cytomegalovirus \\
ADV & adenovirus \\
HSV & herpes simplex virus \\
EBV & Ebstein- Barr virus \\
HHV-6 & Human Herpesvirus-6 \\
HAV & hepatitis A virus \\
HBV & hepatitis B virus \\
HCV & hepatitis C virus \\
VOD & veno-occlusive disease \\
PBSC & peripheral blood stem cells \\
HLH & Hemophagocytic lymphohistiocytosis \\
NHL & Non Hodgkin lymphoma \\
MDS & Myelodysplastic syndrome \\
EBV-PTLD & Ebstein-Barr virus related posttransplant lymhoproliferative disease \\
TBI & total body irradiation \\
MAC & myeloablative conditioning \\
RIC & reduced intensity conditioning \\
\hline &
\end{tabular}

Background: Graft versus host disease is a major cause of morbidity and mortality after allogeneic HSCT from unrelated donors. ATLG is commonly used as prophylaxis for GVHD. The studies according to optimum dose of ATLG especially in pediatric patients are limited.

Patients and Methods: Outcomes of 158 pediatric patients, who received ATLG as GVHD prophylaxis for matched unrelated donor HSCT at a dose of $10 \mathrm{mg} / \mathrm{kg}$ (group 1), $20 \mathrm{mg} / \mathrm{kg}$ (group 2) and $30 \mathrm{mg} / \mathrm{kg}$ (group 3) were analyzed retrospectively. The median duration of follow-up was 25.25 months (range, 1.1-79.5 months).

Results: The incidences of acute and chronic GVHD were statistically not different between three groups $(\mathrm{p}=0.55$ and $\mathrm{p}=0.45)$. But TRM at day 100 and OS at the end of follow-up was found significant inferior in patients received ATLG $10 \mathrm{mg} / \mathrm{kg}(\mathrm{p}=0.006, \mathrm{p}=0.004)$. Cox regression analysis showed that ATLG dose of $10 \mathrm{mg} / \mathrm{kg}$ (hazard ratio [HR] 0.500 [95\% CI 0.301-0.829]; $\mathrm{p}=0.007$ ), severe acute GVHD (HR 5.512 [2.02714.993]; $\mathrm{p}=0.001$ ), and having viral infection (HR 2.510 [1.034-6.089]; $\mathrm{p}=0.042$ ) were significant prognostic factors for inferior OS. 
Conclusion: Although ATLG dose of $10 \mathrm{mg} / \mathrm{kg}$ is effective in pediatric patients on acute and chronic GVHD prevention and safe from the point of infection; TRM and OS were superior in ATLG doses [?] $20 \mathrm{mg} / \mathrm{kg}$ with no difference between $20 \mathrm{mg} / \mathrm{kg}$ and $30 \mathrm{mg} / \mathrm{kg}$. So, it could be better to choose ATLG dose of $20 \mathrm{mg} / \mathrm{kg}$ in conditioning regimen for MUD HSCT in pediatric patients, but these observations should be supported with other multicenter prospective studies including larger patient population.

Introduction: Acute and chronic graft versus host disease is major complication and cause of increased mortality after HSCT. Therefore, prevention and prophylaxis of GVHD is more advanced and more appropriate than his subsequent treatment. ATG is administered as part of the transplantation conditioning regimen to reduce the incidence and severity of GVHD by in vivo T-cell depletion. ATG has got horse- or rabbitderived three formulation: ATGAM (equine lymphocytes; Pfizer), Thymoglobulin (rabbit-derived, whole thymus; Sanofi-Genzyme) or Grafalon (anti-human T-lymphocyte immunoglobulin ATLG); rabbit-derived Jurkat cells; Neovi]. Rabbit-derived ATG formulations are found more effective in GVHD prophylaxis. Furthermore, ATG preparations can differ in GVHD prophylaxis in potency and dose due to different production methods. Although there are number of studies which compare different ATG formulations, most of the studies are with Thymoglobulin and in adult patients. Determination of the optimal dose of ATLG is important in prophylaxis and treating GVHD. Different centers use different doses of ATLG, that are toxic and intense, in part of conditioning regimen. In a number of studies, the dose of ATLG varies from $15 \mathrm{mg} / \mathrm{kg}$ to $60 \mathrm{mg} / \mathrm{kg}$. In some adult HSCT units, a dose of ATLG $60 \mathrm{mg} / \mathrm{kg}$ was even used without a significance reduction in GVHD risk in comparison of lower doses, but at the same time the risk of infections and the development of relapse significantly increase. ${ }^{4}$ The studies according to optimum dose of ATLG especially in pediatric patients are extremely limited. Most of the studies which analyzed the dosing were combined studies, including adults and pediatrics. ${ }^{2}$ Therefore; we compared outcomes (risk of acute and chronic GVHD, VOD, relapse, infection, OS, TRM) of patients, who received ATLG at a dose of $10 \mathrm{mg} / \mathrm{kg}$, $20 \mathrm{mg} / \mathrm{kg}$ and $30 \mathrm{mg} / \mathrm{kg}$.

Patients and methods: One hundred and fifty-eight pediatric patients (median age: 6.66 years; range 0.3-18.8), who received ATLG for GVHD prophylaxis for MUD ( $\mathrm{n}=85 ; 10 / 10$ matched and $\mathrm{n}=73 ; 9 / 10$ matched) HSCT between January 2014 and June 2020 were enrolled in this retrospective study. Patients' characteristics were summarized in table 1 . Patients were divided in three subgroups; ATLG was given to 71 patients (group 1) at a dose of $10 \mathrm{mg} / \mathrm{kg}$, to 52 patients (group 2) at a dose of $20 \mathrm{mg} / \mathrm{kg}$ and to 35 patients (group 3) at a dose of $30 \mathrm{mg} / \mathrm{kg}$ on 3 or 4 consecutive days before HSCT. To prevent serum sickness; $1 \mathrm{mg} / \mathrm{kg}$ methylprednisolone and $1 \mathrm{mg} / \mathrm{kg}$ pheniramine maleate were administered twice each day intravenously before and after 6 hours from start of ATLG administration.

Hundred and thirty-five patients received a myeloablative regimen, 23 patients received reduced intensity conditioning regimen. Stem cell source was bone marrow in 101 patients and peripheral blood stem cells in 57 patients. GVHD prophylaxis consisted of calcineurin inhibitors as combination CSA+MTX in most of the patients $(\mathrm{n}=54 ; 34.1 \%)$. MMF was added routinely to patients with ABO mismatched donors for GVHD prophylaxis up to 60 days. All patients received acyclovir prophylaxis against CMV infection until discontinuation of immunosuppression. Intravenous immunoglobulin was given weekly during inpatient treatment and thereafter according to immunoglobulin $\mathrm{G}$ level $<6 \mathrm{~g} / \mathrm{L}$.

PCR screening tests for CMV was performed routinely weekly in transplantation period and every 14 days in postengraftment period. BK virus was tested in urine and blood only in clinical suspicion of hemorrhagic cystitis. ADV antigen and CMV PCR were tested in stool in patients with diarrhea. Serology for other herpesviruses (HSV, EBV, HHV-6 viruses), parvovirus B19, and hepatitis viruses (HAV, HBV, HCV) was assessed also in clinical suspicion.

The lymphocyte count $>1000 / \mathrm{mm}^{3}$ analyzed in all enrolled patients. Neutrophil engraftment day was defined as the first day of three consecutive days with absolute neutrophil count $>0.5 \times 10^{9} / \mathrm{L}$. Platelets engraftment day was defined as the first of three consecutive days without transfusion support for at least seven days. Lymphocyte engraftment was defined as the first day of three consecutive days with absolute lymphocyte count $>0.5 \times 10^{9} / \mathrm{L}$. 
VOD, acute and chronic GVHD were defined according to the EBMT Guideline. ${ }^{5-7}$

All data were analyzed using the SPSS, version 22.0 for Windows (SPSS, Chicago, IL, USA) statistical package. Categorical data are presented as frequency and percentage (\%). Continuous variables are presented as median, minimum and maximum. The comparisons among groups were made by Kruskal-Wallis for continuous variables with non-normal distribution and a chi-square test for categorical variables. Paired-sample t-test was used for the comparison of dependent variables. A two tailed $p$ value $<0.05$ was considered statistically significant. Univariable and multivariable logistic regression analyses were performed to identify factors independently associated with GVHD, relapse, and survival outcomes. Overall survival (OS) and relapse free survival (RFS) analysis were computed using the Kaplan-Meier method. Univariate and multivariate analyses for OS were performed using the Cox proportional hazard method.

\section{Results:}

The conditioning regimen, the median CD34 + cells of the grafts, engraftment days of neutrophils, platelets and lymphocytes, and the day lymphocyte count $>1000 / \mathrm{mm} 3$, existing of acute/chronic GVHD, VOD and relapse are summarized in table 1 and 2. The median duration of follow-up was 25.25 months (range, 1.1-79.5 months).

ATLG treatment was generally well tolerated except minor infusion related reactions. All recipients could receive ATLG safely with premedication before infusion. There were no serious adverse events attributable to ATLG.

The median time to lymphocyte engraftment in the whole group was 21 days (range, 9-146 days), with no statistically significant difference between three groups (group 1; 22 days vs group 2; 21 days vs group 3; 19 days), but the day, when the lymphocyte count was greater than $1000 / \mathrm{mm}^{3}$, was significantly earlier in group 3 patients than others (group 1; 31 days vs group $2 ; 34$ days vs group $3 ; 25.5$ days $\mathrm{p}=0.03$ ). Higher doses of ATLG did not affect the median neutrophil and platelet engraftment days significantly (table 2).

Acute grade I-II and grade III-IV GVHD were observed $27.2 \%$ and $31 \%$ of all patients. $36.6 \%$ of group 1 patients, $30.8 \%$ of group 2 patients and $20 \%$ of group 3 patients had severe acute GVHD ([?]grade III). The incidences of mild-moderate chronic GVHD and severe chronic GVHD were $9.9 \%$ and $8.5 \%$ in group 1 patients; $5.9 \%$ and $13.7 \%$ in group 2 patients; $2.9 \%$ and $5.7 \%$ in group 3 patients respectively. The incidences of acute and chronic GVHD were statistically not different between three groups $(\mathrm{p}=0.55$ and $\mathrm{p}=0.45$ ). Having multiple viral infection (odds ratio [OR] 3.243 [95\% CI 1.504-6.994]; $\mathrm{p}=0.003$ ) and 9/10 matched unrelated donor (OR 2.557 [95\% CI 1.042-6.278]; $\mathrm{p}=0.040$ ) were factors associated to a greater risk of acute GVHD in multivariate analyses (table 3).

VOD was observed $25.7 \%$ in group 1 patients, $26.9 \%$ in group 2 patients and $25.7 \%$ in group 3 patients. The 5 -year cumulative incidence of relapse in group 1 patients with malignant diseases was $12.7 \%$ versus \%3.8 in group 2 patients and \%8.6 in group 3 patients $(\mathrm{p}>0.05)$. One hundred and seventy-four viral episodes were documented within follow-up. Most of the viral reactivations (93.7\%) occurred during the first three months post-HSCT. One hundred and fifteen patients (72.8\%) had at least one viral infection, 51 patients $(32.3 \%)$ had multiple viral infection. The percentage of patients, who experienced at least one identified viral infection (group 1,74.6\% vs group $2,73.1 \%$ vs group $3,68.6 \%$ ) and multiple viral infection (group 1 , $32.4 \%$ vs group $2,30.8 \%$ vs group $3,37.3 \%$ ), was similar between three groups. The statistical analyses of infection rates were also insignificant between three groups. Only HHV6 reactivation was more frequent in group 3 patients $(14.3 \%, \mathrm{p}=0.004)$. CMV was the most prevalent viral infection $(\mathrm{n}=100,63.3 \%)$ followed by $\mathrm{BK}$ virus $(\mathrm{n}=41,26.1 \%)$ among whole group. BK virus associated hemorrhagic cystitis was second most seen viral infection. Thirty-five cases were associated with symptoms of grade I-II acute GVHD and fortyfour cases were associated with symptoms of grade III-IV acute GVHD at the time of virus detection. The incidence of other viral infections was summarized in table 2 .

Patients diagnosed with malignant and nonmalignant diseases were analyzed separately. We did not find any differences between three ATLG groups in terms of acute and chronic GVHD, relapse, engraftment, viral 
infection rates, TRM and OS in both groups ( $\mathrm{p}>0.05)$.

Eleven recipients of the allogeneic grafts died during the first 100 days post-HSCT. The cumulative incidences of TRM for the whole patients were $6.9 \%$ at day 100 . Thirty-nine patients died at the end of follow-up. The cumulative incidences of TRM for the whole patients were $20.3 \%$ at the end of follow-up (32/158 patients). TRM at the end of follow-up was not statistically significant between three groups $(\mathrm{p}=0.05)$, but TRM at day 100 was found statistically significant higher in group 1 patients (group 1, 14.1\% vs. group 2, 1.9\% vs. group $3,0 \% ; \mathrm{p}=0.006)$.

The probability of overall survival at day 100 and at 6 year was $89.9 \%$ and $74.6 \%$ for the whole study population: $87.3 \%$ and $63.2 \%$ for group 1 patients, $98.1 \%$ and $84.3 \%$ for group 2 patients and $97.1 \%$ and 85.4\% for group 3 patients. Severe acute GVHD (OR 0.088 [95\% CI 0.024-0.323]; p $<0.0001$ ), ATLG groups (OR 2.343 [95\% CI 1.206-4.554]; $\mathrm{p}=0.012$ ), and 9/10 matched unrelated donor (OR 3.237 [95\% CI 1.0879.642]; $\mathrm{p}=0.035$ ) were factors that affect patients' survival in multivariate analyses (table 3 ). ATLG dose of $10 \mathrm{mg} / \mathrm{kg}$ (Group 1), severe acute GVHD and having multiple viral infections were factors associated in both univariate and multivariate analyses to a greater risk of inferior OS $(\mathrm{p}=0.003, \mathrm{p}=0.001$ and $\mathrm{p}=0.028)$. Cox regression analysis showed that ATLG dose of $10 \mathrm{mg} / \mathrm{kg}$ (hazard ratio [HR] 0.500 [95\% CI 0.301-0.829]; $\mathrm{p}=0.007$ ), severe acute GVHD (HR 5.512 [2.027-14.993]; $\mathrm{p}=0.001$ ), and having one (HR 0.356 [0.134-0.948]; $\mathrm{p}=0.039$ ) or multiple viral infection (HR 2.510 [1.034-6.089]; $\mathrm{p}=0.042$ ) were significant prognostic factors for inferior OS (table 4). ATLG administration did significantly affect OS (OR 2.343 [95\% CI 1.206-4.554]; $\mathrm{p}=0.012$ ), TRM at day 100 (OR 0.071 [95\% CI 0.007-0.707]; $\mathrm{p}=0.024$ ) and non-relapse mortality (OR 0.47 [95\% CI 0.26-0.85]; $\mathrm{p}=0.013$ ), but not relapse incidence (OR 0.87 [95\% CI 0.43-1.79]; $\mathrm{p}=0.71$ ). Comparison of OS at the end of follow-up between three groups were associated with significantly inferior survival in group 1 patients ( $\log$ rank test, $\mathrm{p}=0.004$, figure 1 ). Although transplantation with myeloablative conditioning regimen and peripheral blood as stem cell source and 9/10-matched unrelated donor, was not a risk factor for inferior OS at the end of follow-up between 3 groups ( $\mathrm{p}=0.14)$, OS was found $66.7 \%$ in patients treated with $10 \mathrm{mg} / \mathrm{kg}$ ATLG, $80 \%$ in patients treated with $20 \mathrm{mg} / \mathrm{kg}$ ATLG and $93.8 \%$ in patients treated with 30 $\mathrm{mg} / \mathrm{kg}$ ATLG at the end of follow-up in this subgroup. RFS was $77.8 \%$ in group 1 patients, $100 \%$ in group 2 patients and $100 \%$ in group 3 patients $(\mathrm{p}=0.12)$. The overall survival and the cumulative incidences of transplant related mortality were summarized in table 2 .

Discussion: Antithymocyte globulin is most widely used GVHD prophylaxis agent in most of all MUD HSCT regimens. The preventive effect of ATG, both on acute and chronic GVHD, has been reported in numerous retrospective or phases 2 studies. ${ }^{8,9}$ ATG has been shown in randomized clinical trials to decrease mainly chronic GVHD. ${ }^{10-15}$ Most of these studies are adult studies and they discuss mainly thymoglobulin as type of ATG formulation. There are extremely limited data about the optimum dose of this drug in children. Our study is the second study with 158 pediatric patients, which compares different doses of ATLG in GVHD prophylaxis in pediatric patients. Our main finding was that, a reduction in the ATLG dose to $10 \mathrm{mg} / \mathrm{kg}$ did not affect the incidence of acute or chronic GVHD. But TRM and OS at the end of follow-up was found statistically significant better in group 2 and group 3 patients with ATLG treatment 20 $\mathrm{mg} / \mathrm{kg}$ and $30 \mathrm{mg} / \mathrm{kg}$. Also, we found that, ATLG dose of $10 \mathrm{mg} / \mathrm{kg}$, severe acute GVHD, and having viral infection were significant prognostic factors for inferior OS.

Since malignant diseases represents the most frequent indication of HSCT in adults, there are a number of studies about GVHD prophylaxis in malignant diseases in adult patients. But previous studies about the role of ATG/ATLG in MUD HSCT for nonmalignant diseases in adults are extremely rare. There is only one report from the EBMT Severe Aplastic Anemia (SAA) Working Party, with large numbers of patients, which states the beneficial role of in vivo T-cell depletion with ATG or Alemtuzumab with a significant survival benefit, but they conclude that alemtuzumab reduced the risk of acute and chronic GVHD compared with ATG and indicates that alemtuzumab might be the serotherapy of choice for MSD and MUD transplants for SAA. ${ }^{17}$ There is not any recommended dose for ATG/ATLG in their report. In the pediatric setting, there is no large prospective or retrospective randomized multicenter study on the optimal dose of ATLG in MUD HSCT of nonmalignant diseases. In English literature, the first (and only) study, which reports 
different doses of ATLG in GVHD prophylaxis in pediatric patients, is an Italian groups' study. ${ }^{16}$ In this prospective randomized study, Locatelli et al. compared 2 different doses $(30 \mathrm{mg} / \mathrm{kg}$ vs $15 \mathrm{mg} / \mathrm{kg})$ of ATLG in children with hematological malignancies and showed that a lower dose resulted in improved OS and EFS. They stated that children with hematological malignancies given an MUD HSCT should receive low-dose $(15 \mathrm{mg} / \mathrm{kg})$ instead of high-dose $(30 \mathrm{mg} / \mathrm{kg})$ ATLG to avoid the increased risk of non-relapse mortality and subsequent decreased probability of event-free survival. But we found exactly opposite result in our study that patients had improved OS and TRM when ATLG was used [?]20 mg/kg, but no survival advantage between doses of $20-30 \mathrm{mg} / \mathrm{kg}$. In our study, we have a heterogeneous study population. When we analyzed patients diagnosed with malignant and nonmalignant diseases as separate groups, no differences were found between three ATLG groups in both groups in terms of acute and chronic GVHD, relapse, engraftment, viral infection rates, TRM and OS.

In line with previous studies, the preventive effect of ATG/ATLG on GVHD is mostly significant by protecting for chronic GVHD. In recent years, multiple large, randomized studies investigating transplantation outcomes following ATG have been published. Finke et al. studied the impact of ATLG (total dose 60 $\mathrm{mg} / \mathrm{kg}$ ) vs. no ATG on grade III-IV acute GVHD mortality in unrelated transplants after myeloablative conditioning in the first 100 days and they reported that the use of ATLG did not decrease the risk of grades III to IV acute GVHD or death within 100 days, but it resulted in improved severe GVHD-free and relapsefree survival at $34 \%$ versus $13 \%(\mathrm{p}=0.0003) .{ }^{11}$ Similarly, in a randomized, open-label, multicenter study, Kroger et al. found that in myeloablative matched sibling transplants that using ATLG $(30 \mathrm{mg} / \mathrm{kg})$, ATLG was associated with a decreased incidence of chronic GVHD with no impact on OS. ${ }^{14}$ Finally, in the first double-blind randomized study, Soiffer et al. presented ATLG $(60 \mathrm{mg} / \mathrm{kg})$ versus placebo for myeloablative MUD HSCT. ${ }^{4}$ In this study, ATLG significantly reduced acute grades II to IV GVHD and moderate to severe chronic GVHD. Contrary to previous reports, however, OS was worse in the ATLG arm in part because of irradiation-containing preparative regimen. In a sole pediatric randomized study, Locatelli et.al reported that, the 100-day cumulative incidence of grade II-IV acute GVHD was $36 \%$ in the $15 \mathrm{mg} / \mathrm{kg}$ ATLG group and $29 \%$ in the $30 \mathrm{mg} / \mathrm{kg}$ ATLG group $(\mathrm{p}=0.26)$. Chronic GVHD was clinically extensive in 12 (eight- $10 \%$ vs. four-5\%) patients with no difference seen between the two groups. ${ }^{16}$ They stated that, a reduction in the ATLG dose to $15 \mathrm{mg} / \mathrm{kg}$ did not affect the time to engraftment and, more importantly, the incidence of acute or chronic GVHD. In our study, the frequency of grade III-IV acute GVHD observed to be less with higher doses ATLG therapy; 36.6\% in $10 \mathrm{mg} / \mathrm{kg}$ ATLG group, $30.8 \% \mathrm{in} 20 \mathrm{mg} / \mathrm{kg}$ ATLG group and $20 \%$ in $30 \mathrm{mg} / \mathrm{kg}$ ATLG group. Chronic GVHD was 8.5\% clinically severe in group 1 patients and $13.7 \%$ in group 2 patients and $5.7 \%$ in group 3 patients. Like their study, our results indicated also, dose reduction does not affect significantly the incidences of both acute and chronic GVHD ( $\mathrm{p}>0.05)$.

A further concern about using ATLG is related to infection risk. There are studies, which reported that, patients treated with higher doses of ATLG showed higher incidence of CMV infections and EBVPTLD. ${ }^{11,12,19}$ On the other hand, in a Canadian trial and in an HLA identical sibling trial, no differences were found regarding CMV infections and EBV-PTLD between patients randomized to receive or not receive ATLG. ${ }^{13,14}$ We showed that higher dose ATLG $(20-30 \mathrm{mg} / \mathrm{kg})$ did not increase the incidence of viral infections such as CMV, EBV, Parvovirus, BK virus, Adenovirus in pediatric MUD HSCT, but HHV6 reactivation was more frequent in group 3 patients.

The risk of relapse is another major concern for the use of ATLG, despite no significant increase reported in most trials. ${ }^{20-22}$ Instead, Soiffer et al. reported a greater relapse risk and a decreased survival in the subgroup of patients receiving TBI in the preparative regimen. ${ }^{15}$ Our study demonstrated no significant difference in relapse risk between lower or higher doses of ATLG, and RFS was insignificant between three groups. So, higher doses of ATLG did not increase relapse risk in malignant patients in our study.

This study has some limitations, such as its retrospective design and the lack of a pharmacokinetic data. Despite these limitations, there is an extremely limited study, which focused only on pediatric patients. Moreover, we have a long follow-up (median 25.25 months (range, 1.1-79.5 months) and patients' number enrolled to study is big enough, to make a conclusion. We demonstrated that ATLG dose of $10 \mathrm{mg} / \mathrm{kg}$ is 
effective in pediatric patients on acute and chronic GVHD prevention and safe from the point of infection because of rapid immune reconstitution. But; TRM and OS were superior in ATLG doses [?]20 mg/kg, but no difference was observed between $20 \mathrm{mg} / \mathrm{kg}$ and $30 \mathrm{mg} / \mathrm{kg}$. Since severe acute GVHD, ATLG doses, and 9/10 matched unrelated donor were factors that affect patients' survival in our study, it could be better to choose ATLG dose of $20 \mathrm{mg} / \mathrm{kg}$ in conditioning regimen for MUD HSCT in pediatric patients, but these observations should be supported with other multicenter prospective studies including larger patient population. The ATLG dose used in the conditioning regimens should be discussed individually according to the patient's risk factors for GVHD. Also, studies about ATLG pharmacokinetics and pharmacodynamics are still on-going. The effects of low-dose and patient-specific dose ATLG especially in pediatric populations should be assessed in prospective clinical trials.

\section{CONFLICT OF INTEREST}

The authors have no conflict of interest to disclose.

\section{AUTHORS' CONTRIBUTIONS}

D. A.: Concept/design, Data collection, Data analysis/interpretation, Drafting article, Wrote article, Statistics. A.A.: Statistics, Data analysis/interpretation. K.B., S.H., FD.Y., and B.A.: Data collection. G.O.: Concept/design, Critical revision of article, Approval of article

All authors approved the final manuscript as submitted and agree to be accountable for all aspects of the work.

\section{References}

1. Bonifazi F, Rubio MT, Bacigalupo A, et al. Rabbit ATG/ATLG in preventing graft-versus-host disease after allogeneic stem cell transplantation: consensus-based recommendations by an international expert panel. Bone Marrow Transplant. 2020 Jan 22. doi: 10.1038/s41409-020-0792-x. [Epub ahead of print] PubMed PMID: 31969678.

2. Finke J, Schmoor C, Bethge WA, et al. Long-term outcomes after standard graft-versus-host disease prophylaxis with or without anti-human-T-lymphocyte immunoglobulin in haemopoietic cell transplantation from matched unrelated donors: final results of a randomised controlled trial. Lancet Haematol. 2017 Jun;4(6):e293-e301. doi:10.1016/S2352-3026(17)30081-9. PubMed PMID: 28583289.

3. Storek J, Mohty M, and Boelens JJ: Rabbit anti-T cell globulin in allogeneic hematopoietic cell transplantation. Biol Blood Marrow Transplant 2015; 21: pp. 959-970.

4. Soiffer RJ, Kim HT, McGuirk J, et al. Prospective, Randomized, Double-Blind, Phase III Clinical Trial of Anti-T-Lymphocyte Globulin to Assess Impact on Chronic Graft-Versus-Host Disease-Free Survival in Patients Undergoing HLA-Matched Unrelated Myeloablative Hematopoietic Cell Transplantation. J Clin Oncol. 2017 Dec 20;35(36):4003-4011. doi:10.1200/JCO.2017.75.8177. Epub 2017 Oct 17. PubMed PMID: 29040031.

5. Ruutu T, Carreras E. Hepatic Complications. In: Carreras E, Dufour C, Mohty M, Kröger N, eds. Hematopoietic Stem Cell Transplantation and Cellular Therapies, The EBMT Handbook, 7th edn. Springer, Cham;2019:374. https://doi.org/10.1007/978-3-030-02278-5.

6. Holler E, Greinix H, Zeiser R. Acute Graft-Versus-Host disease. In: Carreras E, Dufour C, Mohty M, Kröger N, eds. Hematopoietic Stem Cell Transplantation and Cellular Therapies, The EBMT Handbook, 7th edn. Springer, Cham;2019:323-330. https://doi.org/10.1007/978-3-030-02278-5.

7. Wolff D, Lawitschka A. Chronic Graft-Versus-Host disease. In: Carreras E, Dufour C, Mohty M, Kröger N, eds. Hematopoietic Stem Cell Transplantation and Cellular Therapies, The EBMT Handbook, 7th edn. Springer, Cham;2019:331-345. https://doi.org/10.1007/978-3-030-02278-5.

8. Kuriyama K, Fuji S, Inamoto Y, Tajima K, Tanaka T, Inoue Y, et al. Impact of low-dose rabbit anti-thymocyte globulin in unrelated hematopoietic stem cell transplantation. Int $\mathrm{J}$ Hematol. 2016;103(4):453-60.

9. Kawamura K, Kanda J, Fuji S, Murata M, Ikegame K, Yoshioka K, et al. Impact of the presence of HLA 1-locus mismatch and the use of low-dose antithymocyte globulin in unrelated bone marrow 
transplantation. Bone Marrow Transplant. 2017;52(10):1390-8.

10. Bacigalupo A, Lamparelli T, Barisione G, Bruzzi P, Guidi S, Alessandrino PE, et al. Thymoglobulin prevents chronic graft-versushost disease, chronic lung dysfunction, and late transplant-related mortality: long-term follow-up of a randomized trial in patients undergoing unrelated donor transplantation. Biol Blood Marrow Transplant. 2006;12(5):560-5.

11. Finke J, Bethge WA, Schmoor C, Ottinger HD, Stelljes M, Zander AR, et al. Standard graft-versushost disease prophylaxis with or without anti-T-cell globulin in haematopoietic cell transplantation from matched unrelated donors: a randomised, open-label, multicentre phase 3 trial. Lancet Oncol. $2009 ; 10(9): 855-64$.

12. Socie G, Schmoor C, Bethge WA, Ottinger HD, Stelljes M, Zander AR, et al. Chronic graft-versushost disease: long-term results from a randomized trial on graft-versus-host disease prophylaxis with or without anti-T-cell globulin ATG-Fresenius. Blood. 2011;117(23):6375-82.

13. Walker I, Panzarella T, Couban S, Couture F, Devins G, Elemary M, et al. Pretreatment with antithymocyte globulin versus no anti-thymocyte globulin in patients with haematological malignancies undergoing haemopoietic cell transplantation from unrelated donors: a randomised, controlled, openlabel, phase 3, multicentre trial. Lancet Oncol. 2016;17(2):164-73.

14. Kroger N, Solano C, Wolschke C, Bandini G, Patriarca F, Pini M, et al. Antilymphocyte globulin for prevention of chronic graftversus-host disease. N Engl J Med. 2016;374(1):43-53.

15. Soiffer RJ, Kim HT, McGuirk J, Horwitz ME, Johnston L, Patnaik MM, et al. Prospective, randomized, double-blind, phase III clinical trial of anti-T-lymphocyte globulin to assess impact on chronic graft-versus-host disease-free survival in patients undergoing HLA-matched unrelated myeloablative hematopoietic cell transplantation. J Clin Oncol. 2017;35(36):4003-11.

16. Locatelli F, Bernardo ME, Bertaina A, et al. Efficacy of two different doses of rabbit anti-T-lymphocyte globulin to prevent graft-versus-host disease in children with haematological malignancies transplanted from an unrelated donor: a multicentre, randomised, open-label, phase 3 trial. Lancet Oncol. 2017 Aug;18(8):1126-1136.

17. Samarasinghe S, Clesham K, Iacobelli S, et al.; Severe Aplastic Anaemia Working Party of the EBMT. Impact of T-cell depletion strategies on outcomes following hematopoietic stem cell transplantation for idiopathic aplastic anemia: A study on behalf of the European blood and marrow transplant severe aplastic anemia working party. Am J Hematol. 2019 Jan;94(1):80-86. doi: 10.1002/ajh.25314. Epub 2018 Nov 25. PubMed PMID:30328134.

18. Kroger N, Zabelina T, Kruger W, et al. In vivo $\mathrm{T}$ cell depletion with pretransplant anti-thymocyte globulin reduces graft-versus-host disease without increasing relapse in good risk myeloid leukemia patients after stem cell transplantation from matched related donors. Bone Marrow Transplant 2002; 29: 683-689.

19. Podgorny PJ, Ugarte-Torres A, Liu Y, Williamson TS, Russell JA, Storek J. High rabbit-antihuman thymocyte globulin levels are associated with low likelihood of graft-vs-host disease and high likelihood of posttransplant lymphoproliferative disorder. Biol Blood Marrow Transplant 2010; 16: 915-26.

20. Finke J, Bethge WA, Schmoor C, et al. Standard graft-versus-host disease prophylaxis with or without anti-T-cell globulin in haematopoietic cell transplantation from matched unrelated donors: A randomised, open-label, multicentre phase 3 trial. Lancet Oncol. 2009;10:855-864.

21. Walker I, Panzarella T, Couban S, et al. Pretreatment with anti-thymocyte globulin versus no antithymocyte globulin in patients with haematological malignancies undergoing haemopoietic cell transplantation from unrelated donors: a randomised, controlled, open- label, phase 3, multicentre trial. Lancet Oncol. 2016;17:164-173.

22. Bacigalupo A, Lamparelli T, Bruzzi P, et al. Antithymocyte globulin for graft-versus-host disease prophylaxis in transplants from unrelated donors: 2 randomized studies from Gruppo Italiano Trapianti Midollo Osseo (GITMO). Blood. 2001;98:2942-2947.

\section{Hosted file}

Table 1 ATG.pdf available at https://authorea.com/users/370185/articles/488894-comparison-of- 
different-doses-of-anti-human-t-lymphocyte-immunoglobulin-for-graft-versus-host-diseaseprophylaxis-in-pediatric-unrelated-hematopoietic-stem-cell-transplantation

\section{Hosted file}

Table 2 ATG.pdf available at https://authorea.com/users/370185/articles/488894-comparison-ofdifferent-doses-of-anti-human-t-lymphocyte-immunoglobulin-for-graft-versus-host-diseaseprophylaxis-in-pediatric-unrelated-hematopoietic-stem-cell-transplantation

\section{Hosted file}

Table 3 ATG.pdf available at https://authorea.com/users/370185/articles/488894-comparison-ofdifferent-doses-of-anti-human-t-lymphocyte-immunoglobulin-for-graft-versus-host-diseaseprophylaxis-in-pediatric-unrelated-hematopoietic-stem-cell-transplantation

\section{Hosted file}

Table 4 ATG.pdf available at https://authorea.com/users/370185/articles/488894-comparison-ofdifferent-doses-of-anti-human-t-lymphocyte-immunoglobulin-for-graft-versus-host-diseaseprophylaxis-in-pediatric-unrelated-hematopoietic-stem-cell-transplantation

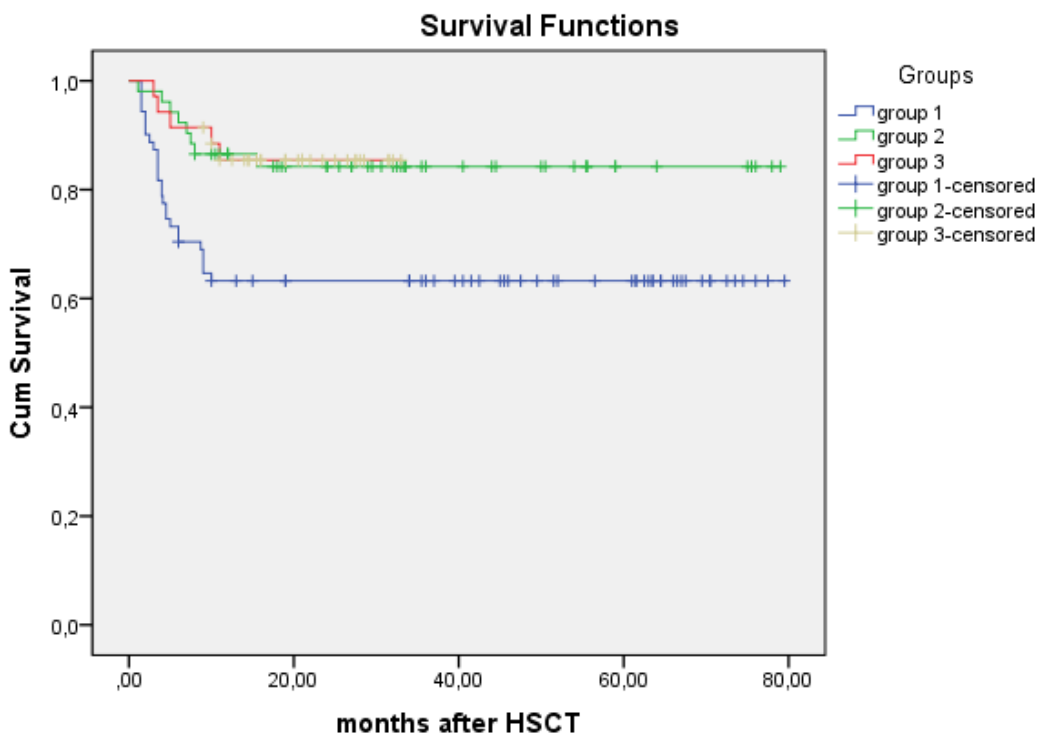

